\title{
Can any agreement be reached on cholesterol lowering?
}

\author{
P N Durrington
}

Reports in the scientific and lay press on the current evidence from epidemiological and clinical trials for the benefit of lowering blood cholesterol often appear to be at variance. In May 1993 the British Hyperlipidaemia Association held a symposium at the Royal College of Physicians ${ }^{1}$ to establish where there was agreement and to produce guidelines to identify people who might live longer as a result of therapy. A series of contentious issues were considered.

Are low concentrations of serum cholesterol associated with an increased risk of death from non-cardiovascular causes

A meta-analysis of 18 separate cohort studies of $150000^{2}$ men presented by $\mathrm{D} R$ Jacobs showed an increasing gradient of risk of death associated with increasing cholesterol for coronary heart disease as well as for all cardiovascular disease. In 11 studies of 120000 women there was a similar gradient for coronary heart disease but not for all cardiovascular disease pooled. In women deaths from coronary heart disease (CHD) accounted for only about half of total cardiovascular mortality. In men a similar effect would be masked by the large number of coronary deaths. The implication of this might be that in women the likelihood of death from non-cardiac vascular diseases, such as stroke, was inversely related to serum cholesterol.

In both men and women the mortality from all non-cardiovascular causes was higher in those with serum cholesterol concentrations $<4 \mathrm{mmol} / 1$. There were similar findings in the Multiple Risk Factor Intervention Trial (MRFIT) of 350000 men. Lipid concentrations as low as $<4 \mathrm{mmol} / \mathrm{l}$ would never be an aim of therapy, so the argument about whether lowering cholesterol causes noncardiovascular disease is perhaps irrelevant. The suggested causal relation between noncardiovascular disease and low cholesterol is challenged by long-term studies that show that low serum cholesterol is associated with chronic ill health for many years before death. A study of men aged 22 who were followed for 42 years showed that not only cardiovascular mortality but also non-cardiovascular mortality increased directly with serum cholesterol concentration. ${ }^{3}$

G Davey Smith pointed out that the MRFIT trial, ${ }^{4}$ cited by Jacobs, showed that men aged 35-39 followed for 12 years demonstrated no relation between cholesterol and non-coronary mortality. The inverse relation was only apparent in elderly men, some of whom would be chronically sick. If the relation were causal, it would be expected in all cohorts. In the Renfrew and Paisley Study cholesterol was inversely related to lung cancer mortality. ${ }^{5}$ However, a cohort of similar size recruited in Glasgow at the same time from people who were all employed and might thus be expected to be more healthy showed no such relation. Furthermore in the Whitehall study when the confounding factors associated with increased mortality and low cholesterol were taken into account the associations between low cholesterol and increased non-coronary mortality were reduced or abolished. ${ }^{6}$ That cholesterol lowering in clinical trials (as opposed to spontaneously low concentrations) does not increase the risk of death from non-coronary disease was evident from a recently published meta-analysis of 35 cholesterol-lowering intervention trials in 57000 patients. ${ }^{7}$ In this the degree to which cholesterol was reduced far from being associated with increasing non-cardiovascular mortality if anything, correlated with its decrease. ${ }^{8}$

One commonly suggested mechanism, by which decreases in serum cholesterol could increase deaths not caused by $\mathrm{CHD}$, is by influencing cell membrane function. However, very low concentrations of cholesterol, have to be achieved for the composition of membranes, even of blood cells, to be affected $^{9}$ and many tissues (the brain in particular) do not rely on low density lipoprotein for their cholesterol supply, which they synthesise themselves. ${ }^{10}$ In inherited disorders such as hypobetalipoproteinaemia in which low cholesterol concentrations are habitually present throughout life longevity rather than premature non-cardiovascular death is the rule. ${ }^{11}$ On balance the evidence suggests that low cholesterol is not in itself a cause of increased mortality.

What is the balance between the advantages and disadvantages of reducing serum cholesterol?

In the meta-analysis presented by Davey Smith, ${ }^{7}$ of all identified randomised controlled trials of cholesterol-lowering treat- 
ments with a follow up of 6 months or more and with at least one death CHD mortality in individual trials differed more than 100-fold. Primary prevention trials clustered at the low end of the range of risk and secondary prevention trials at the upper end. The odds of dying of any cause in the treatment groups as compared with the control groups was significantly related $(p<0.001)$ to the risk of coronary heart disease in the control group. When the annual coronary heart disease mortality exceeded $3 \%$ all-cause mortality decreased in the intervention group, while at lower rates it increased.

An overall benefit of cholesterol lowering in high risk patients was strongly supported by other contributions. Lewis looked specifically at trials in patients with existing ischaemic heart disease ${ }^{712}$ in whom it is known that $50 \%$ of coronary deaths occur. $80 \%$ of all deaths in these trials were caused by coronary heart disease. Lewis also reviewed the findings of coronary angiographic studies that show that regression of coronary disease is possible with lipid-lowering therapy. ${ }^{13-17}$ One of the most striking findings was a $68 \%$ decrease in the need for coronary bypass surgery in patients whose cholesterol was reduced by $23 \%$ by partial ileal bypass surgery. ${ }^{16}$

Holme's meta-analysis, of more than 135000 participants was larger than any other because it included trials in which the intervention was multifactorial and not confined to cholesterol lowering. ${ }^{18} \mathrm{He}$ too concluded that the likelihood of benefit from cholesterol-lowering was greatest in patients at high risk of coronary heart disease. His study indicated that in addition to patients with established coronary disease, symptomfree individuals with the highest cholesterol concentrations also stood to benefit.

The benefits of lowering cholesterol are therefore clearest in those with declared ischaemic heart disease and those with high cholesterol concentrations. There is no evidence of any beneficial effects on all cause mortality in symptomfree people with a mild or moderate increase in lipids.

Why is there no favourable effect on all cause mortality in those without a high risk of coronary death?

There was disagreement about the explanation for this lack of effect. Davey Smith maintained that there was an increase in non-cardiac death in cholesterol-lowering trials involving drug treatment (but not in trials that did not involve drugs) and that this increase nullified any beneficial effect in trials where there were few coronary deaths. R Peto and $\mathbf{R}$ Collins, however, were critical of Davey Smith's meta-analysis and believed that some of the trials he had included were unsuitable. In their meta-analysis of 22 trials of 42000 people they too found a small increase in non-cardiac deaths in the intervention groups, but this did not relate to any specific cause and probably arose by chance.
The total number of people participating in the trials was too small to yield sufficiently large numbers of deaths to draw any reliable conclusion.

The reason for the lack of favourable effect on all cause mortality in low risk individuals remains unexplained.

\section{Are there particular high risk groups?}

G R Thompson described some of the high risk syndromes in which current evidence favours the introduction of lipid-lowering drugs even in the absence of CHD if dietary therapy alone proves ineffective. Patients with genetic hyperlipidaemia, particularly those with familial hypercholesterolaemia and type III hyperlipoproteinaemia, and people in whom polygenic dyslipidaemia was combined with multiple risk factors, such as a family history of ischaemic heart disease, diabetes mellitus, hypertension, and a long history of heavy cigarette smoking were often at sufficiently high risk to justify drug treatment. ${ }^{19} 20$ Thompson also discussed the increased risk posed by hypercholesterolaemia when it was combined with raised concentrations of triglycerides and low concentrations of HDL cholesterol. $\mathrm{He}$ considered that fibrinogen and lipoprotein (a) would soon play an important part in risk assessment. What is really needed is a means of calculating individual coronary risk, but this does not exist at present because none of the prospective studies has included all the risk factors. Nevertheless many patients with hypercholesterolaemia, who are clearly at high coronary risk, are not receiving treatment. In the United Kingdom less than $10 \%$ of the population have had their serum cholesterol measured compared with $40 \%$ in many other European countries.

\section{Is there a consensus view?}

One conclusion from the symposium was that there was clear evidence that lowering cholesterol in those at higher risk of coronary disease was beneficial. Population approaches to cholesterol lowering based on dietary modification are justified, but the benefits of lipid lowering medication are only evident in people at high coronary risk. Currently, for those in the middle of the risk range conclusions about lipid-lowering drugs are not entirely reliable and therapeutic decisions must be based on clinical judgement. There is a strong case for mounting a clinical trial of one of the more recently developed lipid-lowering drugs, which may have a more favourable benefit:risk ratio and might thus be indicated in patients at lower risk.

\section{Practical considerations}

The decision to introduce cholesterol-lowering medication should not be taken on the basis of the absolute concentration of cholesterol itself, but rather on an assessment of overall coronary risk. ${ }^{21}$ An important issue for 
Recommendations of British Hyperlipidaemia Association on priorities and cut-off values for lipid-lowering drug therapy for hypercholesterolaemia persisting after institution of dietary treatment

\begin{tabular}{llll}
\hline Priority & Patient category & $\begin{array}{l}\text { Total } \\
\text { cholesterol } \\
\text { (mmol/l) }\end{array}$ & $\begin{array}{l}\text { LDL } \\
\text { cholesterol } \\
\text { (mmol/l) }\end{array}$ \\
\hline First & $\begin{array}{l}\text { Patients with established CHD, } \\
\text { including post-CABG, angioplasty, } \\
\text { or cardiac transplant, or with other } \\
\text { significant atherosclerosis } \\
\text { Patients with genetically determined } \\
\text { hyperlipidaemia (for example, familial } \\
\text { hypercholesterolaemia) or with } \\
\text { multiple risk factors (family history } \\
\text { diabetes, mellitus, hypertension, } \\
\text { long history of smoking) }\end{array}$ & $>5.2$ & $>3.5$ \\
Third & $\begin{array}{l}\text { Men without evidence of atherosclerosis } \\
\text { or other risk factors }\end{array}$ & $>6.5$ & $>5.0$ \\
Fourth & $\begin{array}{l}\text { Post-menopausal women` without } \\
\text { evidence of other risk factors }\end{array}$ & $>7.8$ & $>6.0$ \\
\hline
\end{tabular}

*Take account of premature menopause or low HDL cholesterol. It may be more appropriate to consider hormone replacement therapy before lipid lowering medication.

those responsible for issuing guidelines for the management of hyperlipidaemia is what is the level of absolute risk at which benefit from treating raised cholesterol concentrations might accrue? Davey Smith highlighted this by showing that many of the published guidelines particularly those from the United States $^{22}$ go far beyond any reasonable interpretations of the evidence and are particularly open to criticism because they recommend the use of lipid-lowering drugs at lower levels of risk in women than they do in men. The British Hyperlipidaemia Association guidelines (table), by assigning patients to different orders of priority according to the certainty with which risk can be established and the strength of the evidence in favour of treatment are designed to overcome this problem.

\section{Shortcomings of current evidence}

Meta-analysis, whatever its appeal to statisticians, cannot be more than a rough guide to the clinical value of intervention. Many of the trials included in meta-analysis were shortterm, lasting less than 2 years. In the metaanalysis presented by Peto and Collins the decrease in the incidence of coronary heart disease in trials lasting less than 2 years was $9 \%$ whereas in trials lasting longer it was $22 \%$. Many of the trials included in the metaanalyses were analysed on an intention-totreat basis. That means that patients who did not comply with medication were included in the intervention group. In the Lipid Research Clinic Trial it was evident that the decrease in cholesterol in the intervention group as a whole was $8 \%$ and the decrease in coronary incidence $10 \% .{ }^{23}$ It was estimated that in the patients who complied fully with medication the decrease in cholesterol was $25 \%$ and the decrease in coronary incidence $49 \%$. Intention-to-treat analysis is the only unbiased way to analyse a trial, but the result it gives is qualitative: a quantitatively greater benefit is likely to accrue in clinical practice. This view could be challenged if the incidence of adverse side effects were related to cholesterol-lowering, but it is known that non-cardiovascular deaths are unrelated to cholesterol reduction ${ }^{724}$ or even to compli- ance with medication. ${ }^{25}$ Also in clinical practice it is now possible to identify particular patterns of hyperlipidaemia for which certain lipid lowering drugs are particularly suited: in clinical trials published so far only one choice or agent was available. For all these reasons the $3 \%$ annual decrease in death from coronary heart disease where all-cause mortality is decreased in clinical trials, as established by Davey Smith et al, ${ }^{7}$ will be at least halved in clinical practice.

Furthermore attempts to use prospective studies to assess the levels of coronary risk in patients identified by the guidelines may underestimate the risk because of regression dilution bias. In most prospective studies one measurement of cholesterol made at the outset is related to the subsequent incidence of events. No matter how large the study is this procedure is going to underestimate the risk associated with factors such as cholesterol or blood pressure. ${ }^{26}$ This is because of biological and analytical variation in the initial measurement. A participant in a prospective study categorised as being in the upper range for cholesterol on the basis of one measurement is more likely to have a true mean value (which can only be estimated as the mean of several measurements) that is lower than the initial value rather than higher. At the lower end of the scale the opposite is the case. The effect of this is that the relation between mean cholesterol and risk is steeper by about half as much again than that reported in studies employing single measurements which are frequently used to estimate risk. Taking this into account a man of 55 with a cholesterol of $7.8 \mathrm{mmol} / 1$ (normal triglycerides and low density lipoprotein cholesterol $6.0 \mathrm{mmol} / \mathrm{l}$ ) and no other risk factors would have an annual risk of coronary death of $1 \%$ predicted from Framington data. ${ }^{27}$ If the value of $7 \cdot 8$ $\mathrm{mmol} / \mathrm{l}$ was established after a series of readings as is recommended in the British Hyperlipidaemia Association guidelines the risk is probably closer to $1.5 \%$. Additionally it is likely that the risk attaching to a cholesterol concentration of $7.8 \mathrm{mmol} / 1$ when it has been achieved as the result of reduction from a previously higher value by dietary treatment will be greater than for a similar spontaneous concentration.

\section{British Hyperlipidaemia Association guidelines}

Present evidence is consistent with benefit for priorities as low as the third category (table). The lowest priority (women with cholesterol $>7.8 \mathrm{mmol} / 1$ and no other risk factor) would certainly include some patients in whom evidence of benefit was equivocal, but if serum high density lipoprotein cholesterol were low or the cholesterol concentration were substantially greater than $7.8 \mathrm{mmol} / \mathrm{l}$, the risk of coronary heart disease could be sufficiently high to justify lipid-lowering drug therapy if diet were not effective enough. The relatively low priority in women is because of the limited trial data in women, the uncertainty 
about optimum cholesterol concentrations in women, and the likelihood that lipoprotein concentrations with which many clinicians are unfamiliar must be taken into account. This argument is not intended to apply to women with established genetic hyperlipidaemia, atherosclerosis or multiple risk factors, particularly diabetes. Furthermore, age at the menopause is important in assessing cardiovascular risk and hormone replacement therapy should frequently be considered before lipid lowering drug treatment as a means of reducing cardiovascular risk.

\section{Conclusion}

There seems to be more agreement about the evidence for the benefit of lipid lowering than is apparent from recent reports in the scientific and lay press. Use of the four categories of priority allows individual physicians to make their own decisions about the level at which they will actively intervene. It is important in the United Kingdom to ensure that those people in the highest categories of risk; who could benefit from current knowledge about lipid lowering treatment, do receive it. At present too few do. It is, however, equally important that some who do not stand to benefit are not ill-advisedly prescribed such treatment. Both groups would benefit from improvements in medical practice.

I thank Dr G Davey Smith of the University of Glasgow Department of Public Health for providing valuable comments on an earlier draft of this paper.

1 British Hyperlipidaemia Association Symposium Cholesterol-lowering trials. Advice for the British Cholesterol-lowering trials. Advice for the British
Physician. eds: Laker $M$, Neil A, Wood C. London: Physician. eds: Laker M, Neil A, Wood C.
Royal College of Physicians of London, 1993.

2 Jacobs D, Blackburn H, Higgins $M$, et al. Report of the conference on low blood cholesterol: mortality associations. Circulation 1990;96:1046-60.

$3 \mathrm{Klag}$ MJ, Ford DE, Mead LA, He J, Whelton PK, Liang $\mathrm{K}$, Levine $\mathrm{DM}$. Serum cholesterol in young men and subsequent cardiovascular disease. $N$ Engl $f \mathrm{Med}$ 1993;328:313-8.

4 Sherwin R, Wentworth D, Culter J, Hulley SB, Kuller L, Stamler J. Serum cholesterol levels and cancer mortality in 361,662 men screened for the Multiple Risk Factor Intervention Trial. $\mathcal{F} A M A$ 1988;287:943-8.

5 Isles CG, Hole DJ, Gillis CR, Hawthorne VM, Lever AF. Plasma cholesterol, coronary heart disease, and cancer in the Renfrew and Paisley survey. BMF 1989;298 $920-4$.

6 Davey Smith G, Shipley MJ, Marmot MG, Rose G. Plasma cholesterol concentration and mortality: The Whitehall Study. FAMA 1992;267:70-6.
7 Roussouw JE, Lewis B, Rifkind BM. The value of lowering cholesterol after myocardial infarction. $N$ Engl $\mathcal{F}$ Med 1990;323:1112-9.

8 Davey Smith G, Song F, Sheldon TA. Cholesterol lowering and mortality: the importance of considering initial evel of risk $B M 9$ 1993:306:1367-73.

9 Marenah CB, Lewis BM, Hassall D, et al. Hypocholesterolaemia and non-cardiovascular disease: metabolic studies on subjects with low plasma cholesterol concentrations. BMF 1983;282:1603-6.

10 Dietschy JM. In Low Blood Cholesterol-Health Implications eds: Lewis B, Tikkanen MJ, Pauleth R. London, Current Medical Literature 1993 (in press).

11 Kahn JA, Glueck CJ. Familial hypobetalipoproteinaémia Absence of atherosclerosis in post-mortem study. $¥ A M A$ 1978;240:47-8.

12 Roussouw JE, Connor PL, Hulley SB. Deaths from injury, violence and suicide in secondary prevention trials of cholesterol-lowering. $N$ Engl $f$ Med 1991;325: 1813 .

13 Cashin-Hemphill L, Mack WJ, Pogoda JM, Sanmarco ME, Azen SP, Blakenhorn DH. Beneficial effects of colestipol-niacin on coronary atherosclerosis. $¥ A M A$ colestipol-niacin

14 Kane JP, Mallory MJ, Ports TA, Phillips NR, Diehl JC, Havel RJ. Regression of coronary atherosclerosis during reatment of familial hypercholesterolemia with combined drug regimens. $\mathscr{f} A M A$ 1990;264:3007-12.

15 Brown G, Albers J, Fisher LD, et al. Regression of coronary artery disease as a result of intensive lipid-lowering therapy in men with high levels of apolioprotein B. N Engl $\mathscr{f}$ Med 1990;323:1289-98.

16 Buchwald H, Varco RL, Malts JP, et al. Effect of partial ileal bypass surgery on mortality from coronary heart disease in patients with hypercholesterolemia-report from the Program on the Surgical Control of Hyperlipidaemias (POSH) $N$ Engl $\mathcal{F}$ Med 1990;323: 946-55.

17 Watts GF, Lewis B, Brunt JNH, et al. Effects on coronary artery disease of lipid-lowering diet, or diet plus cholestyramine - in the St. Thomas' Atheroscleros Regression Study (STARS) Lancet 1992;339:563-9.

18 Holme I. An analysis of randomised trials evaluating the effect of cholesterol reduction on total mortality and coronary heart disease incidence. Circulation 1990;82:1916-24

19 Thompson GR. Primary hyperlipidaemia. Br Med Bull 1990;46:986-1004.

20 Durrington PN. Hyperlipidaemia: diagnosis and management. London: Wright, 1989.

21 Durrington PN. Hyperlipidaemia: should we treat paticnts? Should we treat populations? What treatment should we use? Chapter 3 In: Rowland DJ, ed. Recent ould in cardiology Edinburgh: Churchill Livingstone, 1992; Vol II, 47-71.

22 McIsaac WJ, Naylor CD, Basinski A. Mismatch of coronary risk and treatment intensity under the National nary risk and treatment intensity under the National Med 1991;6:518-23.

23 Lipid Research Clinics Program. The Lipid Research Clinics Coronary Prevention Trial Results II: The relationship of reduction in incidence of coronary heart distionship of reduction in incidence of coronary heart

24 Committee of Principal Investigators. Report on a cooperative trial in the primary prevention of ischaemic heart disease using clofibrate. $B r$ Heart $\mathcal{f}$ 1978;40 1069-188

25 Wysowski DK, Gross TP. Deaths due to accidents and violence in two recent trials of cholesterol-lowerin drugs. Arch Intern Med 1990;150:2169-72.

26 MacMahon S, Peto R, Cutler J, et al. Blood pressure, stroke and coronary heart disease. Part I Prolonged differences in blood pressure: prospective observational studies corrected for the regression dilution bias. Lancet 1990;335:765-74.

27 Kannel WB. Metabolic risk factors for coronary heart disease in women: perspective from the Framington Study. Am Heart $\mathcal{F}$ 1987;114:413-9. 